\title{
Association of anemia and long-term survival in patients with pulmonary hypertension
}

\author{
Richard A. Krasuski a,*, Stephen A. Hart ${ }^{\mathrm{a}, \mathrm{b}}$, Brad Smith ${ }^{\mathrm{c}}$, Andrew Wang ${ }^{\mathrm{d}}$, \\ J. Kevin Harrison ${ }^{d}$, Thomas M. Bashore ${ }^{\mathrm{d}}$ \\ a Division of Cardiovascular Medicine, Cleveland Clinic Foundation, Cleveland, OH, United States \\ ${ }^{\mathrm{b}}$ Cleveland Clinic Lerner College of Medicine of Case Western Reserve University, Cleveland, OH, United States \\ c Altarum Institute, San Antonio, TX, United States \\ d Division of Cardiology, Department of Medicine, Duke University Medical Center, Durham, NC, United States
}

\section{A R T I C L E I N F O}

\section{Article history:}

Received 30 November 2009

Received in revised form 31 March 2010

Accepted 14 April 2010

Available online 15 May 2010

\section{Keywords:}

Anemia

Clinical outcomes

Hemoglobin

Pulmonary hypertension

\begin{abstract}
A B S T R A C T
Background: Anemia is a marker of worsened clinical outcome in patients with heart failure from left ventricular dysfunction. Pulmonary hypertension often results in right ventricular dysfunction. Accordingly we sought to examine the association of hemoglobin levels and long-term all-cause mortality in a cohort of patients with pulmonary hypertension.

Methods: Baseline demographic information, clinical characteristics and fasting blood work were obtained in a cohort of 145 patients with pulmonary hypertension referred for pulmonary vasodilator testing. Data was retrospectively analyzed with Cox-proportional hazards analysis.

Results: Baseline characteristics of the cohort included age (mean \pm SD) $55.8 \pm 14.6$ years, 75\% women, 50\% with idiopathic pulmonary hypertension, mean pulmonary artery pressure $46.1 \pm 14.2 \mathrm{~mm} \mathrm{Hg}$ and arterial $\mathrm{O}_{2}$ saturation $91 \pm 6 \%$. The most commonly utilized pulmonary hypertension specific therapeutic agents in descending order of frequency were epoprostenol (27\%), sildenafil (21\%), bosentan (17\%), and treprostinil (6\%). Over a median follow-up of 2.1 years, there were 39 deaths (26.9\%). Patients who died had significantly lower hemoglobin levels than those survived (12.2 \pm 2.3 vs. $13.7 \pm 2.0, p<0.001)$. After adjustment for known predictors of death and pulmonary hypertension etiology, anemic patients were 3.3 times more likely to die than non-anemic patients (95\% CI [1.43-7.51], $p=0.005)$.

Conclusions: Hemoglobin levels closely parallel survival in pulmonary hypertension. Modification of anemia in this disorder could alter the clinical course and calls for further research in this area.
\end{abstract}

(c) 2010 Elsevier Ireland Ltd. All rights reserved.

\section{Introduction}

Anemia is a strong, independent risk factor for morbidity and mortality in a number of chronic conditions including kidney disease [1] and cancer [2]. It also negatively influences the course of acute illnesses [3] including myocardial infarction [4,5] and increases periprocedural and perioperative morbidity and mortality [6,7]. By the classic World Health Organization definition [8], anemia is present in only $\sim 9 \%$ of the United States population, but becomes significantly more common in older adults and in patients with comorbid illness $[9,10]$. In certain conditions such as cancer and chronic kidney disease, anemia has a well-described pathophysiological basis and is nearly ubiquitous; while in other conditions the mechanism is less clear and attributed to the so-called "anemia of chronic disease" [11]. A number

\footnotetext{
* Corresponding author. Desk J2-4, Cardiovascular Medicine, Cleveland Clinic Foundation, 9500 Euclid Ave. Cleveland, OH 44195, United States. Tel.: +1 210445 7433; fax: +12104456163.

E-mail address: krasusr@ccf.org (R.A. Krasuski).
}

of studies have described an increased prevalence of anemia in patients with heart failure (HF) resulting from left ventricular (LV) dysfunction [12,13]. Anemia occurs in up to $20 \%$ of outpatients and $30 \%$ of hospitalized patients with HF. In HF patients anemia is associated with an increased risk of cardiovascular events and is an independent predictor of mortality [14-16].

Pulmonary hypertension $(\mathrm{PH})$ is a devastating clinical disorder associated with progressive right ventricular (RV) dysfunction and high rates of mortality. Patients with PH and RV dysfunction appear to have significantly worse clinical outcomes despite several new therapies $[17,18]$. The range of hemoglobin levels in patients with $\mathrm{PH}$ has not been previously established. Furthermore, the effect of $\mathrm{PH}$ on erythropoiesis appears more complex than in left ventricular (LV) dysfunction. Low cardiac output, one of the postulated mechanisms of anemia in patients with LV dysfunction [19], is also prevalent in $\mathrm{PH}$ owing to RV dysfunction. On the other hand, hypoxia is also quite common, particularly in patients with idiopathic pulmonary hypertension, and $\mathrm{PH}$ from interstitial lung disease, collagen-vascular disease, and cyanotic congenital heart disease. Hypoxia stimulates 
erythropoiesis and may therefore counteract the effect of RV failure. This study was designed to retrospectively investigate the prevalence of anemia in a cohort of patients with $\mathrm{PH}$ referred for vasodilator testing, and to examine its association with long-term all-cause mortality.

\section{Methods \\ 2.1. Patients}

Consecutive patients with pulmonary hypertension were entered into a database between November 1998 and December 2007 at two tertiary care academic affiliated medical centers. Complete blood counts were collected from a fasting blood-draw on either the morning of or the evening prior to cardiac catheterization. Abnormal values were repeated for validation purposes and only stable hemoglobin measurements were used for analysis. The World Health Organization classification of anemia $(<12 \mathrm{~g} / \mathrm{dL}$ for females, $<13 \mathrm{~g} / \mathrm{dL}$ for males) was used for this study [8]. Although this definition remains far from optimal, no other clinically relevant definition is uniformly accepted. The updated clinical classification of pulmonary hypertension (Dana Point) was used in this study [20]. Briefly, class 1 consists of pulmonary arterial hypertension, class 2 consists of pulmonary venous hypertension from left heart disease, class 3 is associated with lung diseases and/or hypoxia, class 4 includes chronic thrombotic and/or embolic disease and class 5 is a miscellaneous category.

Patients underwent cardiac catheterization expressly for vasodilator testing or as part of their diagnostic work-up prior to further clinical intervention. Exclusion criteria included patients with comorbid diseases strongly associated with anemia such as renal failure (serum creatinine $\geq 2.5$ ) or sickle cell anemia, patients with class 2 pulmonary hypertension (left heart disease) and cyanotic congenital heart disease. This study was approved by the Duke University Medical Center and the Cleveland Clinic Institutional Review Boards.

\subsection{Hemodynamic assessment}

All studies were conducted in the fasting state and with minimal sedation. If a left heart catheterization was performed, all contrast injections were performed after hemodynamic assessments were completed. Right heart catheterization was performed using a single end-hole, balloon flotation catheter (Bard Pulmonary Wedge Catheter, Medtronic or Balloon Wedge Pressure Catheter, Arrow International, Inc.). Baseline hemodynamic measurements included mean right atrial pressure (RA), right ventricular systolic and diastolic pressures, pulmonary artery (PA) systolic, diastolic, and mean pressures, mean pulmonary capillary wedge (PA occlusive) pressure, and femoral artery systolic, diastolic, and mean pressures. In repeat measurements during inhalation of $40 \mathrm{ppm}$ of nitric oxide (INO Therapeutics; Clinton, NJ), administration included PA systolic, diastolic, and mean pressures, mean pulmonary capillary wedge pressure and femoral artery systolic, diastolic, and mean pressures.

Blood samples were obtained from the main PA and femoral artery for calculation of the cardiac output using an assumed Fick method. Systemic and pulmonary vascular resistances were calculated using standard hemodynamic equations and are presented in absolute (Wood) units. A positive response to inhaled nitric oxide (iNO) was defined by a drop in PA pressure $\geq 10 \mathrm{~mm} \mathrm{Hg}$ to a mean pulmonary artery pressure $\leq 40 \mathrm{~mm} \mathrm{Hg}$ [21].

\subsection{Clinical assessment and follow-up}

All patients underwent full clinical evaluation at the time of initial referral for cardiac catheterization. Baseline studies included chest radiography, chest computed tomography if chest radiography was abnormal, ventilation-perfusion scanning, full pulmonary function testing, electrocardiography and echocardiography. Patients were followed at regularly scheduled intervals and medical therapy was administered at the discretion of the referring physicians. Vital status was determined using the Social Security Death Index.

\subsection{Statistical analysis}

Data are presented as mean \pm standard deviation for continuous variables and as percentage for discrete variables. Comparison of dichotomous variables was performed using the Pearson chi square test or Fisher's exact test when appropriate. Comparisons of continuous variables between groups were performed using two-sided $t$-tests and one-way analysis of variance. Statistical significance was assumed with $p<0.05$. Survival analyses were performed using the Kaplan-Meier and proportional hazards regression methods. The proportional hazards model was constructed using previously defined predictors developed from robust patient cohorts and PH etiology [22-24]. Assumptions of the proportional hazard model were verified graphically. Statistically significant differences in the survival functions were assessed with the Wilcoxon test. All analyses were performed using JMP version 7.0 (ㄷ SAS Institute; Cary, NC).

\section{Results}

\subsection{Patient characteristics}

One hundred sixty nine patients were entered into the database between November 1998 and December 2007 and underwent invasive hemodynamic assessment including vasodilator challenge with iNO. Two patients with moderate or worse renal insufficiency (serum creatinine $\geq 2.5$ ), 1 patient with sickle cell anemia, 13 patients with cyanotic congenital heart disease, and 7 patients with Dana Point Class 2 pulmonary hypertension were excluded. Blood counts for one patient were not complete. Of the 145 patients in the final analysis, 39 died (26.9\%) over a median follow-up period of 2.1 years (range 0.01 years to 5.3 years).

Demographics of the cohort stratified by vital status at the completion of the follow-up period are listed in Table 1. Hemoglobin levels for the entire cohort ranged from 8.4 to $18.2 \mathrm{mg} / \mathrm{dL}$ and 38 patients $(26.2 \%)$ were considered anemic using the World Health Organization definition [8]. In females the median hemoglobin level was $13.0 \mathrm{mg} / \mathrm{dL}$ with an interquartile range of 11.9 to $14.7 \mathrm{mg} / \mathrm{dL}$ and in males the median hemoglobin level was $14.3 \mathrm{mg} / \mathrm{dL}$ with an interquartile range of 12.8 to $15.5 \mathrm{mg} / \mathrm{dL}$. Both males and females who died during follow-up had lower baseline hemoglobin levels compared with those who survived $(12.7 \pm 2.2$ vs. $14.3 \pm 2.0, p=0.04$ and $12.1 \pm 2.3$ vs. $13.5 \pm 1.9, p=0.001)$.

Patients who died during the follow-up were older (61.8 \pm 14.8 vs. $53.5 \pm 14.0$ years, $p=0.002)$, had more advanced functional impairment $(11 / 56 / 33$ vs. $33 / 50 / 17 \%$ NYHA class II/III/IV, $p=0.01)$, had worsened renal function $(1.1 \pm 0.4 \mathrm{vs} .0 .9 \pm 0.3$ serum creatinine $\mathrm{mg} / \mathrm{dL}$, $p=0.02$ ), and had lower oxygen saturations ( $89.0 \pm 7.4$ vs. $92.0 \pm 4.8 \%$, $p=0.01$ ). The etiology of $\mathrm{PH}$, in accordance to the 2009 Updated Clinical Classification of Pulmonary Hypertension [20], did not appear to impact survival $(p=0.93)$ nor did the diagnosis of idiopathic pulmonary hypertension $(p=0.32)$.

\subsection{Hemodynamic findings}

Baseline hemodynamic values, again stratified by final vital status, are listed in Table 2. Survivors had lower right-sided filling pressures (RA: $9.9 \pm 5.8$ vs. $12.8 \pm 7.0 \mathrm{~mm} \mathrm{Hg}, p=0.01$, PA: $44.1 \pm 13.4$ vs. $51.5 \pm$ $14.8 \mathrm{~mm} \mathrm{Hg}, p=0.005)$. Lower pulmonary vascular resistance was also associated with survival ( $8.1 \pm 6.1$ vs. $11.4 \pm 7.8$ Wood units, $p=0.009$ ). Seventeen percent of patients experienced a positive vasodilator challenge to iNO defined by a drop in PA pressure of at least $10 \mathrm{~mm} \mathrm{Hg}$ to a value less than $40 \mathrm{~mm} \mathrm{Hg}$. Survivors were no more likely to have experienced a positive response than those that died (19.2 vs. $10.5 \%, p=0.22$ ).

\subsection{Treatment during follow-up}

During follow-up, 2 patients underwent cardiopulmonary surgery (one pulmonary thromboembolectomy and one tricuspid valve repair for severe tricuspid regurgitation) and 3 patients received lung transplantations. The most commonly utilized therapeutic agents in descending order of frequency were warfarin (49\%), calcium channel blockers (34\%), continuous flow oxygen (32\%), angiotensin converting enzyme inhibitors or angiotensin II receptor blockers (29\%), epoprostenol (27\%), spironolactone (22\%), sildenafil (21\%), bosentan (17\%), statins (17\%), digoxin (14\%) and treprostinil (6\%). No significant differences in drug utilization were seen among patients stratified by hemoglobin status.

\subsection{Anemia characteristics}

Clinical characteristics of the cohort stratified by anemic status are shown in Table 3. Patients who were anemic were older $(60.8 \pm 17.0$ 
Table 1

Baseline characteristics of pulmonary hypertensives stratified by vital status at completion of follow-up period.

\begin{tabular}{|c|c|c|c|c|}
\hline & $\begin{array}{l}\text { All patients } \\
(n=145)\end{array}$ & $\begin{array}{l}\text { Survivors } \\
(n=106)\end{array}$ & $\begin{array}{l}\text { Deaths } \\
(n=39)\end{array}$ & $p$-value ${ }^{a}$ \\
\hline Age (years) & $55.8 \pm 14.6$ & $53.5 \pm 14.0$ & $61.8 \pm 14.8$ & 0.002 \\
\hline Female & 75.2 & 75.5 & 74.4 & 0.89 \\
\hline Race & & & & 0.41 \\
\hline Caucasian & 77.9 & 80.2 & 71.8 & \\
\hline African American & 18.6 & 16.0 & 25.6 & \\
\hline Other $^{b}$ & 3.4 & 3.8 & 2.6 & \\
\hline Dana Point Classification ${ }^{c}$ & & & & $0.93^{\mathrm{d}}$ \\
\hline Class 1 & 69.7 & 69.8 & 69.2 & \\
\hline Class 3 & 24.1 & 23.6 & 25.6 & \\
\hline Class 4 & 2.8 & 3.8 & 0 & \\
\hline Class 5 & 3.4 & 2.8 & 5.1 & \\
\hline Idiopathic PH & 50.3 & 52.8 & 43.6 & 0.32 \\
\hline NYHA Class & & & & 0.01 \\
\hline II & 27.5 & 33.3 & 11.1 & \\
\hline III & 51.4 & 50.0 & 55.6 & \\
\hline IV & 21.0 & 16.7 & 33.3 & \\
\hline Anemic status & 26.2 & 18.9 & 46.2 & 0.001 \\
\hline Hemoglobin level (mg/dL) & $13.3 \pm 2.1$ & $13.7 \pm 2.0$ & $12.2 \pm 2.3$ & $<0.001$ \\
\hline Males & $13.9 \pm 2.2$ & $14.3 \pm 2.0$ & $12.7 \pm 2.2$ & 0.04 \\
\hline Females & $13.2 \pm 2.1$ & $13.5 \pm 1.9$ & $12.1 \pm 2.3$ & 0.001 \\
\hline Systemic hypertension & 29.7 & 31.1 & 25.6 & 0.52 \\
\hline Diabetes & 16.6 & 17.9 & 12.8 & 0.46 \\
\hline Atrial fibrillation & 12.4 & 9.4 & 20.5 & 0.07 \\
\hline Serum sodium $(\mathrm{mg} / \mathrm{dL})$ & $139.2 \pm 3.5$ & $139.3 \pm 3.4$ & $138.7 \pm 3.8$ & 0.31 \\
\hline Serum creatinine $(\mathrm{mg} / \mathrm{dL})$ & $1.0 \pm 0.3$ & $0.9 \pm 0.3$ & $1.1 \pm 0.4$ & 0.02 \\
\hline Arterial $\mathrm{O}_{2}$ saturation (\%) & $91.0 \pm 5.9$ & $92.0 \pm 4.8$ & $89.0 \pm 7.4$ & 0.01 \\
\hline
\end{tabular}

Continuous variables are presented as mean \pm standard deviation (SD) or frequency (\%). Definition of abbreviations: NYHA $=$ New York Heart Association; $\mathrm{PH}=$ pulmonary hypertension; $\mathrm{O}_{2}=$ oxygen

a $p$-values relate to comparisons between survivors and decedents.

b Includes Asian/Pacific Islander, Hispanic, and Native American.

c From the 2009 Updated Clinical Classification of Pulmonary Hypertension [20].

d Class 1 vs. Class 3 vs. others.

vs. $54.0 \pm 13.4$ years, $p=0.01)$, had worse functional class $(30 / 35 / 35$ vs. $27 / 57 / 16 \%$ NYHA II/III/IV, $p=0.02$ ), had a higher baseline RA pressure $(12.6 \pm 7.0$ vs. $10.0 \pm 5.9, p=0.03)$, and lower baseline PVR $(6.8 \pm 4.1$ vs. $9.7 \pm 7.3$ Wood units, $p=0.03)$. Anemic patients were more likely to have Dana Point class 1 etiology when compared to class 3 and class $4 / 5$ etiologies $(p=0.02)$. Dana Point class 3 patients had elevated hemoglobin levels when compared to the rest of the cohort which was expected due to underlying lung disease although the trend was not significant $(13.8 \pm 2.3$ vs. $13.2 \pm 2.1, p=0.13)$. Renal function did not appear to influence anemic status as serum creatinine between anemics and non-anemics was virtually identical $(1.0 \pm 0.4$ vs. $1.0 \pm 0.3, p=0.43)$.

Table 2

Hemodynamic values of pulmonary hypertensives stratified by vital status at completion of follow-up period.

\begin{tabular}{|c|c|c|c|c|}
\hline & $\begin{array}{l}\text { All patients } \\
(n=145)\end{array}$ & $\begin{array}{l}\text { Survivors } \\
(n=106)\end{array}$ & $\begin{array}{l}\text { Deaths } \\
(n=39)\end{array}$ & $p$-value ${ }^{a}$ \\
\hline Mean RA pressure (mm Hg) & $10.7 \pm 6.3$ & $9.9 \pm 5.8$ & $12.8 \pm 7.0$ & 0.01 \\
\hline Mean PA pressure $(\mathrm{mm} \mathrm{Hg})$ & $46.1 \pm 14.2$ & $44.1 \pm 13.4$ & $51.5 \pm 14.8$ & 0.005 \\
\hline Cardiac output (L/min) & $4.5 \pm 1.5$ & $4.7 \pm 1.5$ & $4.2 \pm 1.5$ & 0.08 \\
\hline PVR (Wood units) & $9.0 \pm 6.7$ & $8.1 \pm 6.1$ & $11.4 \pm 7.8$ & 0.009 \\
\hline Mean aortic pressure $(\mathrm{mm} \mathrm{Hg})$ & $98.0 \pm 15.2$ & $98.7 \pm 16.0$ & $96.0 \pm 12.7$ & 0.36 \\
\hline SVR (Wood units) & $22.3 \pm 8.8$ & $22.2 \pm 8.7$ & $22.6 \pm 9.4$ & 0.82 \\
\hline Responders to $\mathrm{iNO}^{\mathrm{b}}(\%)$ & 16.6 & 18.9 & 10.3 & 0.22 \\
\hline
\end{tabular}

Continuous variables are presented as mean \pm standard deviation (SD) or frequency (\%). Definition of abbreviations: $\mathrm{RA}=$ right atrial; $\mathrm{PA}=$ pulmonary arterial; $\mathrm{PVR}=$ pulmonary vascular resistance; $\mathrm{SVR}=$ systemic vascular resistance; $\mathrm{iNO}=$ inhaled nitric oxide.

a-values relate to comparisons between survivors and decedents.

b Response to inhaled nitric oxide defined as a drop in PA pressure of at least $10 \mathrm{~mm} \mathrm{Hg}$ to a mean PA pressure $<40 \mathrm{~mm} \mathrm{Hg}$.
Available medical records were reviewed to further characterize patients' anemia. Anticoagulation therapy prior to catheterization was present in $2 / 3$ of patients receiving anticoagulation during the followup period but demonstrated no association with anemic status $(p=0.59)$ at the time of catheterization. Available hematologic data demonstrated no difference in mean corpuscular volume $(87.9 \pm 9.0$ vs. $90.2 \pm 5.4 \mathrm{fL}, p=0.23$ ) and slightly elevated red cell distribution width $(17.5 \pm 2.3$ vs. $14.7 \pm 1.7 \%, p<0.001)$ between anemics and non-anemics.

To investigate the effect of high hemoglobin levels we compared patients in the highest hemoglobin quartile against all others for each sex ( $>15.5 \mathrm{~g} / \mathrm{dL}$ for males and $>14.7 \mathrm{~g} / \mathrm{dL}$ for females). Of the 34 patients in the highest hemoglobin quartile only 4 died $(11.8 \%)$. Patients who died were less likely to be in the highest hemoglobin quartile than those that survived $(10.3 \%$ vs. $28.3 \%, p=0.02)$. There were 13 patients with elevated hemoglobin levels using the upper limits of normal for standard hemoglobin measurement at our institution ( $>17 \mathrm{~g} / \mathrm{dL}$ for males and $>16 \mathrm{~g} / \mathrm{dL}$ for females) and only 2 died during follow-up $(15.4 \%, p=0.30)$. Using this definition no difference was seen in the proportion of patients that had elevated hemoglobin ( $5.1 \%$ vs. $10.4 \%, p=0.30$ ).

\subsection{Mortality according to hemoglobin status}

Kaplan-Meier survival analysis demonstrated that anemic patients had significantly worse survival ( $p=0.001$ ) (Fig. 1). The hazard ratio for anemia was 3.2 (95\% CI [1.7-6.1]). To assess the independent effect of hemoglobin level on mortality, we developed a proportional

Table 3

Baseline characteristics and selected hemodynamic values of pulmonary hypertensives stratified by hemoglobin status.

\begin{tabular}{|c|c|c|c|}
\hline Parameter & $\begin{array}{l}\text { Anemic }^{\mathrm{a}} \\
(n=38)\end{array}$ & $\begin{array}{l}\text { Normal } \\
(n=107)\end{array}$ & $\begin{array}{l}p- \\
\text { value }\end{array}$ \\
\hline Death during follow-up, no. (\%) & $18(47.4)$ & $21(19.6)$ & 0.001 \\
\hline Age (years) & $60.8 \pm 17.0$ & $54.0 \pm 13.4$ & 0.01 \\
\hline Female & 73.7 & 75.7 & 0.80 \\
\hline Race & & & 0.39 \\
\hline Caucasian & 81.6 & 76.6 & \\
\hline African American & 18.4 & 18.7 & \\
\hline Other $^{\mathrm{a}}$ & 0 & 4.7 & \\
\hline Dana Point Classification ${ }^{\mathrm{b}}$ & & & $0.02^{\mathrm{c}}$ \\
\hline Class 1 & 84.2 & 64.5 & \\
\hline Class 3 & 15.8 & 27.1 & \\
\hline Class 4 & 0 & 3.7 & \\
\hline Class 5 & 0 & 4.7 & \\
\hline Idiopathic PH & 52.6 & 49.5 & 0.74 \\
\hline NYHA Class & & & 0.02 \\
\hline II & 29.7 & 26.7 & \\
\hline III & 35.1 & 57.4 & \\
\hline IV & 35.1 & 15.8 & \\
\hline Hemoglobin level (mg/dL) & $10.6 \pm 1.1$ & $14.3 \pm 1.5$ & $<0.001$ \\
\hline Mean RA pressure (mm Hg) & $12.6 \pm 7.0$ & $10.0 \pm 5.9$ & 0.03 \\
\hline Mean PA pressure $(\mathrm{mm} \mathrm{Hg})$ & $43.5 \pm 11.7$ & $47.0 \pm 14.9$ & 0.19 \\
\hline Cardiac output (L/min) & $4.9 \pm 1.5$ & $4.4 \pm 1.4$ & 0.05 \\
\hline PVR (Wood units) & $6.8 \pm 4.1$ & $9.7 \pm 7.3$ & 0.03 \\
\hline Arterial $\mathrm{O}_{2}$ saturation & $92.0 \pm 6.0$ & $90.6 \pm 5.9$ & 0.29 \\
\hline Serum creatinine $(\mathrm{mg} / \mathrm{dL})$ & $1.0 \pm 0.4$ & $1.0 \pm 0.3$ & 0.43 \\
\hline Positive response to iNO ${ }^{d}$ & 13.2 & 17.8 & 0.51 \\
\hline Rx with ACE-inhibitor & 18.0 & 25.2 & 0.39 \\
\hline Rx with epoprostenol & 29.0 & 21.01 & 0.34 \\
\hline
\end{tabular}

Continuous variables are presented as mean \pm standard deviation (SD) or frequency (\%). Definition of abbreviations: $\mathrm{PH}=$ pulmonary hypertension; NYHA = New York Heart Association; $\mathrm{RA}=$ right atrial; $\mathrm{PA}=$ pulmonary arterial; $\mathrm{PVR}=$ pulmonary vascular resistance; $\mathrm{O}_{2}=$ oxygen; $\mathrm{iNO}=$ inhaled nitric oxide; $\mathrm{Rx}=$ prescription; $\mathrm{ACE}=$ angiotensin converting enzyme.

a Includes Asian/Pacific Islander, Hispanic, and Native American.

b From the 2009 Updated Clinical Classification of Pulmonary Hypertension [20].

c Class 1 vs. Class 3 vs. Others.

d Response to inhaled nitric oxide defined as a drop in PA pressure of at least $10 \mathrm{~mm} \mathrm{Hg}$ to a mean PA pressure $<40 \mathrm{~mm} \mathrm{Hg}$. 


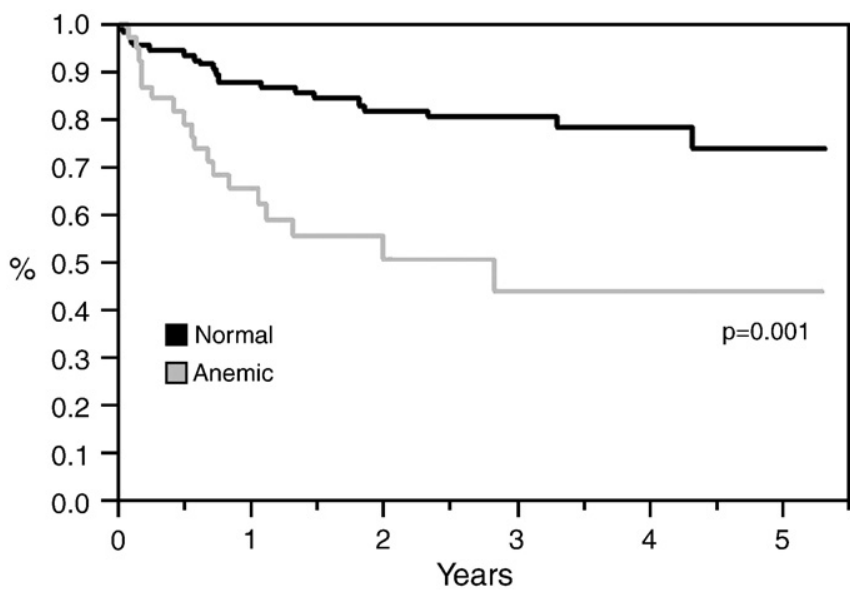

Fig. 1. Survival according to hemoglobin status measured at baseline. Anemia portended significantly worse outcomes during the follow-up period $(p=0.001)$.

hazards regression model to investigate the effects of known predictors of mortality in PH patients including age, NYHA functional class, grade of tricuspid regurgitation, PVR, and PH etiology (Table 4). Using the WHO definition, anemia conferred an adjusted HR of 3.3 (95\% CI [1.43-7.51], $p=0.005)$. Investigating hemoglobin as a continuous variable, each $\mathrm{g} / \mathrm{dL}$ increase in hemoglobin level decreased the hazard of death by $34 \%$ (HR 0.66, 95\% CI [0.52-0.83], $p<0.001$ ) (Table 5).

\section{Discussion}

This study shows for the first time that anemia is common in patients with advanced pulmonary hypertension. More importantly, the presence of anemia appears to have a powerful association with clinical outcome in $\mathrm{PH}$ patients and its prognostic significance is independent of previously described risks for morbidity and mortality and $\mathrm{PH}$ etiology. Anemia, as defined by the WHO, increases the hazard of death by more than 3 fold. Since dichotomization of continuous variables (such as hemoglobin level) can be prone to bias, we also analyzed hemoglobin as a continuous variable and this revealed similarly significant results. Each g/dL increase in hemoglobin level led to a $33 \%$ reduction in the hazard of death in adjusted analysis.

The reduction in hemoglobin levels in our patients did not appear to be related to renal insufficiency as measured by serum creatinine, nor was it driven by depressed cardiac output or counterbalanced by low oxygen saturations. Mechanistically PH has been characterized as a state of enhanced inflammation [25], and several biomarkers including IL-6 have been reported to be elevated in PH patients [26-28]. Under such conditions response to endogenous and exogenous erythropoietin appears to be reduced [29]. Of note, elevations in serum erythropoietin

Table 4

Proportional hazards regression model using WHO definition for anemia.

\begin{tabular}{llll}
\hline Parameter & HR & $95 \% \mathrm{CI}$ & $p$-value \\
\hline Anemia $^{\mathrm{a}}$ (dichotomous) & 3.30 & $1.43-7.51$ & 0.005 \\
Age (by year) & 1.02 & $0.99-1.05$ & 0.14 \\
Dana Point Class 1 & 0.57 & $0.15-3.65$ & 0.49 \\
Dana Point Class 3 $_{\text {WHO functional class }}$ & 0.73 & $0.16-5.13$ & 0.71 \\
Tricuspid regurgitation (grade $^{\mathrm{b}}$ ) & 2.08 & $1.18-3.75$ & 0.01 \\
Baseline PVR (by Wood unit) & 1.63 & $1.15-2.36$ & 0.005 \\
\hline
\end{tabular}

Definition of abbreviations: $\mathrm{WHO}=$ World Health Organization; HR=hazard ratio; $\mathrm{CI}=$ confidence interval; $\mathrm{PVR}=$ pulmonary vascular resistance.

a $<12 \mathrm{~g} / \mathrm{dL}$ for females or $<13 \mathrm{~g} / \mathrm{dL}$ for males [8].

b Tricuspid regurgitation was qualitatively graded as $1=$ none, $2=$ mild, $3=$ moderate, $4=$ severe.
Table 5

Proportional hazards regression model using hemoglobin level as a continuous variable.

\begin{tabular}{lllc}
\hline Parameter & HR & $95 \% \mathrm{CI}$ & $p$-value \\
\hline Hemoglobin level (by g/dL) & 0.66 & $0.52-0.83$ & $<0.001$ \\
Age (by year) & 1.02 & $0.99-1.05$ & 0.16 \\
Modified Evian Class 1 & 0.49 & $0.13-3.2$ & 0.40 \\
Modified Evian Class 3 & 0.64 & $0.14-4.60$ & 0.61 \\
WHO functional class & 1.92 & $1.07-3.50$ & 0.03 \\
Tricuspid regurgitation (by grade ${ }^{\mathrm{a}}$ ) & 1.64 & $1.16-2.35$ & 0.004 \\
Baseline PVR (by Wood unit) & 1.07 & $1.01-1.13$ & 0.03 \\
\hline
\end{tabular}

Definition of abbreviations: $\mathrm{WHO}=$ World Health Organization; HR= hazard ratio; $\mathrm{CI}=$ confidence interval; $\mathrm{PVR}=$ pulmonary vascular resistance.

a Tricuspid regurgitation was qualitatively graded as $0=$ none, $1=$ trivial, $2=$ mild, $3=$ moderate, $4=$ severe.

have recently been shown to be present in patients with HF and portend a worsened clinical outcome [30].

As demonstrated in Tables 1 and 4, the etiology of PH did not appear to influence survival or anemic status. We chose a-priori to exclude patients with comorbid disease associated with anemia to prevent confounding. We also excluded patients with left heart disease (Evian class $2 \mathrm{PH}$ ) because anemia has already been linked to worse outcomes in these patients. Patients with cyanotic heart disease were also excluded because of complex secondary erythrocytosis that could also confound our analysis [31].

The number of vasoreactive patients in our cohort is higher than has been previously reported [32]. In 2005, Sitbon et al. retrospectively reviewed patient data and concluded that less than $10 \%$ of $\mathrm{PH}$ patients were vasoreactive (PA pressure reduction $<10 \mathrm{~mm} \mathrm{Hg}$ to a value $<40 \mathrm{~mm} \mathrm{Hg}$ ). However, their study population had strict hemodynamic inclusion criteria, had worse functional class and utilized two different vasoreactive testing drugs which may confound their results [33]. Our study, however, utilized $40 \mathrm{ppm}$ iNO for each vasodilator challenge.

Pulmonary hypertension is a disorder with serious consequences and high rates of mortality despite aggressive new therapies [34,35]. In our population $60 \%$ of patients received a prostacyclin analogue, an endothelin antagonist or a phosphodiesterase-5 inhibitor and $20 \%$ of these patients received combination therapy. Despite these medications, over a quarter of patients died within 5 years of follow-up. Clearly a need for further therapeutic advances exists in this population. This study provides important insight into a previous undescribed aspect of pulmonary hypertension, low hemoglobin levels.

It is important to note that are limitations to the study design. Although the database was prospectively collected, it was retrospectively analyzed. Therefore, it is not possible to make firm conclusions on the causation of outcome and anemia in pulmonary hypertensive patients, nor about its clinical sequelae. Larger, confirmatory studies will be very valuable in this regard. This study was performed at 2 large medical centers and was therefore subject to referral bias. It is also unknown whether direct therapy such as transfusion or erythropoietin was utilized during the follow-up period, though we could not find any evidence of this through very thorough record review.

Anemia in PH patients may simply be a marker for worsened clinical outcome as has recently been suggested in heart failure patients [36]. In this capacity measurement of hemoglobin could still provide important additional prognostic information in $\mathrm{PH}$ patients, as well as potentially identify which patients may require more aggressive and often more expensive therapies. Alternatively anemia may play a central role in the pathophysiology of $\mathrm{PH}$. Recent studies suggest that the hemoglobin and the erythrocyte play a central role in regulating the activity of nitric oxide in the vasculature $[37,38]$. In particular the deoxygenated form of hemoglobin may directly reduce nitrite to nitric oxide, and anemia could therefore limit this essential step that normally promotes vasodilation of the pulmonary vascular bed. 
Although early trials of erythropoietin treatment in left heart failure demonstrated increased functional capacity, larger randomized trials have shown less benefit $[39,40]$. It is therefore plausible that modifying the anemia of patients with $\mathrm{PH}$ through some yet to be discovered pathway or by administering pre-existent therapies such as erythropoietin may lead to clinical improvement in this challenging disorder.

\section{Funding}

No outside funding was obtained for this study.

\section{Acknowledgement}

The authors of this manuscript have certified that they comply with the Principles of Ethical Publishing in the International Journal of Cardiology [41].

\section{References}

[1] Akizawa T, Pisoni RL, Akiba T, Saito A, Fukuhara S, Asano Y, et al. Japanese haemodialysis anaemia management practices and outcomes (1999-2006): results from the DOPPS. Nephrol Dial Transplant 2008;23(11):3643-53 Nov.

[2] Knight K, Wade S, Balducci L. Prevalence and outcomes of anemia in cancer: systematic review of the literature. Am J Med 2004;116(Suppl 7A):11S-26S Apr 5

[3] Raghavan M, Marik PE. Anemia, allogenic blood transfusion, and immunomodulation in the critically ill. Chest 2005 Jan;127(1):295-307.

[4] Lipsic E, van der Horst IC, Voors AA, van der Meer P, Nijsten MW, van Gilst WH, et al. Hemoglobin levels and 30-day mortality in patients after myocardial infarction. Int J Cardiol 2005 Apr 20;100(2):289-92.

[5] Nikolsky E, Aymong ED, Halkin A, Grines CL, Cox DA, Garcia E, et al. Impact of anemia in patients with acute myocardial infarction undergoing primary percutaneous coronary intervention: analysis from the Controlled Abciximab and Device Investigation to Lower Late Angioplasty Complications (CADILLAC) trial. J Am Coll Cardiol 2004 Aug 4;44(3):547-53.

[6] Nikolsky E, Mehran R, Aymong ED, Mintz GS, Lansky AJ, Lasic Z, et al. Impact of anemia on outcomes of patients undergoing percutaneous coronary interventions. Am J Cardiol 2004 Oct 15;94(8):1023-7.

[7] Karkouti K, Wijeysundera DN, Beattie WS. Reducing Bleeding in Cardiac Surgery (RBC) Investigators. Risk associated with preoperative anemia in cardiac surgery: a multicenter cohort study. Circulation 2008 Jan 29;117(4):478-84.

[8] World Health Organization. Nutritional anemias: report of a WHO Scientific GroupWorld Health Organization. Geneva Switzerland; 1968.

[9] Woodman R, Ferrucci L, Guralnik J. Anemia in older adults. Curr Opin Hematol 2005 Mar;12(2):123-8.

[10] Lucca U, Tettamanti M, Mosconi P, Apolone G, Gandini F, Nobili A, et al. Association of mild anemia with cognitive, functional, mood and quality of life outcomes in the elderly: the "Health and Anemia" study. PLoS ONE 2008 Apr 2;3(4):e1920.

[11] Strippoli GF, Craig JC, Manno C, Schena FP. Hemoglobin targets for the anemia of chronic kidney disease: a meta-analysis of randomized, controlled trials. J Am Soc Nephrol 2004 Dec;15(12):3154-65.

[12] Anand I, McMurray JJ, Whitmore J, Warren M, Pham A, McCamish MA, et al. Anemia and its relationship to clinical outcome in heart failure. Circulation 2004 Jul 13;110 (2):149-54.

[13] Ezekowitz JA, McAlister FA, Armstrong PW. Anemia is common in heart failure and is associated with poor outcomes: insights from a cohort of 12065 patients with newonset heart failure. Circulation 2003 Jan 21;107(2):223-5.

[14] Groenveld HF, Januzzi JL, Damman K, van Wijngaarden J, Hillege HL, van Veldhuisen DJ, et al. Anemia and mortality in heart failure patients a systematic review and meta-analysis. J Am Coll Cardiol 2008;52(10):818-27 Sep 2.

[15] Komajda M, Anker SD, Charlesworth A, Okonko D, Metra M, Di Lenarda A, et al. The impact of new onset anaemia on morbidity and mortality in chronic heart failure: results from COMET. Eur Heart J 2006;27(12):1440-6 Jun.
[16] Szachniewicz J, Petruk-Kowalczyk J, Majda J, Kaczmarek A, Reczuch K, Kalra PR, et al. Anaemia is an independent predictor of poor outcome in patients with chronic heart failure. Int J Cardiol 2003;90(2-3):303-8 Aug.

[17] Chin KM, Kim NH, Rubin LJ. The right ventricle in pulmonary hypertension. Coron Artery Dis 2005 Feb;16(1):13-8.

[18] Park MH. Advances in diagnosis and treatment in patients with pulmonary arterial hypertension. Catheter Cardiovasc Interv 2008;71(2):205-13 Feb 1.

[19] Okonko DO, Anker SD. Anemia in chronic heart failure: pathogenetic mechanisms. J Card Fail 2004 Feb;10(Suppl 1):S5-9.

[20] Simonneau G, Robbins IM, Beghetti M, Channick RN, Delcroix M, Denton CP, et al. Updated clinical classification of pulmonary hypertension. J Am Coll Cardiol 2009;54 (Suppl 1):S43-54 Jun 30.

[21] Barst RJ, McGoon M, Torbicki A, Sitbon O, Krowka MJ, Olschewski H, et al. Diagnosis and differential assessment of pulmonary arterial hypertension. J Am Coll Cardiol 2004;43(Suppl 12 S):40S-7S Jun 16.

[22] Forfia PR, Fisher MR, Mathai SC, Housten-Harris T, Hemnes AR, Borlaug BA, et al. Tricuspid annular displacement predicts survival in pulmonary hypertension. Am J Respir Crit Care Med 2006;174(9):1034-41 Nov 1.

[23] Hlatky MA, Greenland P, Arnett DK, Ballantyne CM, Criqui MH, Elkind MS, et al. Criteria for evaluation of novel markers of cardiovascular risk: a scientific statement from the American Heart Association. Circulation 2009 May 5;119(17): 2408-16.

[24] Wensel R, Opitz CF, Anker SD, Winkler J, Hoffken G, Kleber FX, et al. Assessment of survival in patients with primary pulmonary hypertension: importance of cardiopulmonary exercise testing. Circulation 2002 Jul 16;106(3):319-24.

[25] Dorfmuller P, Perros F, Balabanian K, Humbert M. Inflammation in pulmonary arterial hypertension. Eur Respir J 2003 Aug;22(2):358-63.

[26] Humbert M, Monti G, Brenot F, Sitbon O, Portier A, Grangeot-Keros L, et al. Increased interleukin-1 and interleukin- 6 serum concentrations in severe primary pulmonary hypertension. Am J Respir Crit Care Med 1995 May;151(5):1628-31.

[27] Yoshio T, Masuyama JI, Kohda N, Hirata D, Sato H, Iwamoto M, et al. Association of interleukin 6 release from endothelial cells and pulmonary hypertension in SLE. J Rheumatol 1997 Mar;24(3):489-95.

[28] Damas JK, Otterdal K, Yndestad A, Aass H, Solum NO, Froland SS, et al. Soluble CD40 ligand in pulmonary arterial hypertension: possible pathogenic role of the interaction between platelets and endothelial cells. Circulation 2004 Aug 24;110(8):999-1005.

[29] Del Vecchio L, Pozzoni P, Andrulli S, Locatelli F. Inflammation and resistance to treatment with recombinant human erythropoietin. J Ren Nutr 2005 Jan;15(1):137-41.

[30] van der Meer P, Lok DJ, Januzzi JL, de la Porte PW, Lipsic E, van Wijngaarden J, et al. Adequacy of endogenous erythropoietin levels and mortality in anaemic heart failure patients. Eur Heart J 2008;29(12):1510-5 Jun.

[31] Oechslin E. Hematological management of the cyanotic adult with congenital heart disease. Int J Cardiol 2004;97(Suppl 1):109-15 Dec.

[32] Sitbon O, Humbert M, Jais X, Ioos V, Hamid AM, Provencher S, et al. Long-term response to calcium channel blockers in idiopathic pulmonary arterial hypertension. Circulation 2005 Jun 14;111(23):3105-11.

[33] Ghofrani HA, Wilkins MW, Rich S. Uncertainties in the diagnosis and treatment of pulmonary arterial hypertension. Circulation 2008 Sep 9;118(11):1195-201.

[34] Rubin LJ. Pulmonary arterial hypertension. ProcAmThoracSoc 2006;3(1):111-5.

[35] Rubin LJ, Badesch DB. Evaluation and management of the patient with pulmonary arterial hypertension. Ann Intern Med 2005 Aug 16;143(4):282-92.

[36] Kosiborod M, Curtis JP, Wang Y, Smith GL, Masoudi FA, Foody JM, et al. Anemia and outcomes in patients with heart failure: a study from the National Heart Care Project. Arch Intern Med 2005 Oct 24;165(19):2237-44.

[37] Crawford JH, Isbell TS, Huang Z, Shiva S, Chacko BK, Schechter AN, et al. Hypoxia, red blood cells, and nitrite regulate NO-dependent hypoxic vasodilation. Blood 2006 Jan 15;107(2):566-74.

[38] Gladwin MT, Crawford JH, Patel RP. The biochemistry of nitric oxide, nitrite, and hemoglobin: role in blood flow regulation. Free Radic Biol Med 2004 Mar 15;36 (6):707-17

[39] Ponikowski P, Anker SD, Szachniewicz J, Okonko D, Ledwidge M, Zymlinski R, et al. Effect of darbepoetin alfa on exercise tolerance in anemic patients with symptomatic chronic heart failure: a randomized, double-blind, placebo-controlled trial. J Am Coll Cardiol 2007;49(7):753-62 Feb 20.

[40] van Veldhuisen DJ, Dickstein K, Cohen-Solal A, Lok DJ, Wasserman SM, Baker N, et al. Randomized, double-blind, placebo-controlled study to evaluate the effect of two dosing regimens of darbepoetin alfa in patients with heart failure and anaemia. Eur Heart J 2007;28(18):2208-16 Sep.

[41] Coats AJ. Ethical authorship and publishing. Int J Cardiol 2009;131(2):149-50. 